\title{
CLINICO-MYCOLOGICAL PROFILE OF ONYCHOMYCOSIS IN A TERTIARY CARE CENTRE OF TRIPURA
}

\author{
Manash Debbarma1, Debasis Barman², Tapan Majumdar ${ }^{3}$
}

${ }_{1}^{1}$ Postgraduate, Department of Microbiology, Agartala Government Medical College, Agartala, Tripura.

${ }^{2}$ Assistant Professor, Department of Microbiology, Agartala Government Medical College, Agartala, Tripura.

${ }^{3}$ Associate Professor, Department of Microbiology, Agartala Government Medical College, Agartala, Tripura.

\section{ABSTRACT}

\section{BACKGROUND AND OBJECTIVES}

Onychomycosis is an underreported progressive, recurrent fungal nail infection of human beings. So far, there is no documented study regarding causative agents of Onychomycosis in Tripura. In view of this, the study was conducted in a tertiary healthcare centre of Tripura aiming laboratory diagnosis of Onychomycosis with objectives of, (1) Epidemiology of Onychomycosis among the study subjects, (2) Profiling of aetiological agents.

\section{METHODS}

250 patients with clinical suspicion of Onychomycosis were included in the study. The samples were collected by nail clipping/scrapping. Laboratory diagnosis of Onychomycosis was done by 1) Direct light microscopy to demonstrate fungal elements in $20 \% \mathrm{KOH}$ mount preparation, 2) Fungal cultures for isolation and identification of the aetiological agent.

\section{RESULTS}

Out of 205 immunocompetent cases, 30\% (61/205) and out of 45 immunocompromised cases 53\% (24/45) were suffering from laboratory confirmed cases of Onychomycosis. The patients were from 5-85 years of age. Out of 85 cases, $72.9 \%$ were male. Most affected age group was from 46 to 65 years. Fingernails were affected in $62.5 \%$ cases with predominant clinical presentation as Distal Subungual Onychomycosis (DSOM). In this study, the prevalence of laboratory confirmed Onychomycosis was found to be $34 \%$ (85/250). $85.2 \%$ of the study group comprised of nontribal and $14.8 \%$ tribal population. Among the dermatophytes, Trichophyton mentagrophyte was the commonest isolate though yeasts and nondermatophytic moulds were also found.

\section{INTERPRETATIONS AND CONCLUSIONS}

Onychomycosis is prevalent in all ethnic group (Tribal and Nontribal) of populations of Tripura predominantly affecting adult male. Apart from dermatophytes, several species of Candida and nondermatophytic moulds have been isolated from the onychomycotic lesions. The conventional methods confirm the diagnosis of onychomycosis and the prevalence has been calculated as $34 \%$ of suspected cases. Laboratory diagnosis of Onychomycosis by molecular methods may increase the laboratory confirmation of the diagnosis.

\section{KEYWORDS}

Laboratory Diagnosis, Onychomycosis, Prevalence, Trichophyton Mentagrophyte, Tripura.

HOW TO CITE THIS ARTICLE: Debbarma M, Barman D, Majumdar T. Clinico-mycological profile of onychomycosis in a Tertiary Care Centre of Tripura. J. Evolution Med. Dent. Sci. 2016;5(71):5180-5185, DOI: 10.14260/jemds/2016/1175

\section{INTRODUCTION}

Onychomycosis (OM) is a progressive, recurring fungal infection in human being caused by Dermatophytes, Yeasts and nondermatophyte moulds, which begins in the nail bed and involves the nail plate. The clinical presentation of $\mathrm{OM}$ can be described as a white discoloration of the nails or as thickening, chalkiness and crumbling of the nails. Peeling and fissuring of paronychial nail folds or keratotic debris under the nail edge also maybe evident.[1] The risk factors related to increased prevalence of the disease are heavy perspiration in hot and humid climate going for outdoor activity in barefoot particularly in damp places, minor abrasions to nails, damaged nails in Diabetes Mellitus, impaired peripheral circulation like conditions. The prevalence of the disease

Financial or Other, Competing Interest: None.

Submission 28-07-2016, Peer Review 22-08-2016,

Acceptance 27-08-2016, Published 03-09-2016.

Corresponding Author:

Dr. Tapan Majumdar,

Associate Professor,

Department of Microbiology,

Agartala Government Medical College,

Agartala, Tripura.

E-mail:drtapan1@rediffmail.com

DOI: $10.14260 /$ jemds/2016/1175 varies from 5-50\%. The prevalence increases with the age. In general population, the prevalence is $10 \%$, while in the population belonging to age group 60-70 years, it increases to $20 \%$ and in the population above 70 years of age, the prevalence rises to $50 \%$. Risk of developing onychomycosis is 2-3 times higher in diabetics. In HIV infected patients, the prevalence is $15-40 \%$.[2]

Growing incidence of $\mathrm{OM}$ includes ageing population, an expanding number of Immunocompromised Patients (ICP) like Diabetes Mellitus, Malignancy and (HIV/AIDS) has a major economic impact on the healthcare system. Conventionally, the laboratory diagnosis of OM is based on demonstration of fungal elements in nail clipping/scrapping samples obtained from affected nails in 20\% Potassium Hydroxide solution (KOH) Mount preparation examined under light microscopy and also by fungal culture isolation and identification of aetiological fungi by morphological and biochemical studies. ${ }^{[3]}$ Fungal culture isolation is the Gold standard for diagnosis of OM.

So far, there is no documented study regarding prevalence and aetiological agents causing OM among different ethnic populations including tribal and nontribal populations of Tripura. 
This study aims at laboratory diagnosis of Onychomycosis with objectives of evaluating epidemiology as well as determining the mycological agents responsible in Tripura.

\section{MATERIALS AND METHODS}

The study was conducted in the Department of Microbiology, Agartala; Government Medical College, Tripura, following clearance from the institutional ethical committee.

\section{Study Design}

It was a cross-sectional study consisting of clinically suspected OM. Patients with provisional diagnosis of OM attending the hospital who has given their consent to participate in the study were included. The patients with the history either of traumatic nail damage or with evidence of onychodystrophy due to congenital defect were excluded.

\section{Study Period}

Two years from January, 2013, to December, 2014.

\section{Study Design}

A sample size of 250 cases of suspected OM fulfilling the inclusion criteria has been evaluated. Predesigned clinical data sheets consisting of case history, clinical examination and sample types have been obtained from the study subjects following informed consent.

Nail scrapping/clipping of suspected nails were collected after cleaning the affected area with $70 \%$ ethanol in a properly labelled separate brown paper envelope ${ }^{[3]}$ and transported to the mycology laboratory for further laboratory investigations as follows,

1. $20 \% \mathrm{KOH}$ Mount was examined for direct demonstration of fungal elements.

2. All the samples were inoculated on each pair of (a) Sabouraud Dextrose Agar (SDA) and (b) SDA with 5\% Chloramphenicol and Cycloheximide. One pair from each set were incubated at $25^{\circ} \mathrm{C}$ and $37^{\circ} \mathrm{C}$ respectively for daily examination up to six weeks.

3. Any growth in the culture medium was identified by Lactophenol Cotton Blue (LPCB) mount and doubtful morphological features were confirmed by slide culture. Germ tube test, culture on Corn Meal Agar (CMA) ${ }^{[4]}$ and Carbohydrate fermentation tests $\left.{ }^{[4}\right]$ were performed for confirmation of yeast isolates.

4. Cornmeal agar (HiMedia, India) containing 1\% Tween $80[5]$ in $90 \mathrm{~mm}$ petri plates were prepared and divided in four quadrants. Using straight wire, 2-3 streaks of pure culture inoculum of $3.5-4.0 \mathrm{~cm}$ in length were made keeping $1.2 \mathrm{~cm}$ apart inside a quadrant in the plate. A presterile cover slip was placed covering the portion of the streak producing partially anaerobic environment. Inoculated plate was incubated at $25^{\circ} \mathrm{C}$ for 3-5 days and then examined microscopically under low power objective (10X) first and then high power objective (40X) to observe the morphological features like hyphae, pseudohyphae, blastospores, ascospores, chlamydospores, basidiospore for speciation of yeast isolates.

For carbohydrate fermentation, first the liquid fermentation medium was prepared containing Peptone (1\%), sodium chloride (0.5\%), Andrade's indicator $(0.005 \%)$ and sterilised by autoclaving at $121^{\circ} \mathrm{C}$ at pressure (15 pounds/square inches). Filter sterilised sugar at the concentration of $2 \%$ was added to the medium and poured in pre-sterile test tubes (approx. $5 \mathrm{~mL}$ ) having inverted Durham's Tubes. Sugars like Glucose, Maltose, Sucrose, lactose, Galactose and Trehalose were used during the study. The thick suspension of yeasts grown on sugar-free medium was used for the carbohydrate fermentation assay. Approximately, $0.1 \mathrm{~mL}$ of test suspension was inoculated in each sugar tube and incubated at $25^{\circ} \mathrm{C}$ for 1 week and examined at the intervals of every 48-72 hours. Acid production following carbohydrate fermentation was detected by colour change (pink colour) of inoculated sugar medium tube. Production of gas in the tube was taken as fermentation positive while only acid production indicated that carbohydrate is assimilated.[4]

\section{RESULTS}

During the study period, total number of 250 suspected cases of Onychomycosis were included. Among them, 205 cases were Immunocompetent and 45 were Immunocompromised. Out of 205 immunocompetent cases, 30\% (61/205) and out of 45 immunocompromised cases 53\% (24/45) were suffering from laboratory confirmed cases of Onychomycosis (Table. I). The patients were from 5-85 years of age groups. Out of 85 laboratory confirmed cases, $72.9 \%$ were male. Most affected age group was from 46 to 55 years. Ethnicity distribution shows $85.2 \%(213 / 250)$ nontribal and $14.8 \%$ $(37 / 250)$ tribal populations. Overall frequency of OM among the study subjects estimated to be $34 \%$.

Site of involvement shows $62.5 \%$ (55/85) of the patients presented with fingernail infections remaining $37.5 \%$ $(30 / 85)$ had toenail involvement. Distal subungual onychomycosis were found to be the commonest clinical presentation in $72 \%(61 / 85)$ case (Table. I; Image. I). All other clinical varieties of OM were also found in this study, which may also be seen in Table. II.

$\mathrm{KOH}$ mount preparations of the collected samples showed presence of fungal elements in 25\% (62/250) cases. Remaining $75 \%(188 / 250)$ were negative for any fungal elements, whereas culture showed growth in 32\% (80/250) of cases. Detailed distribution of $\mathrm{KOH}$ and Culture results are presented in Table. III. Out of 80 culture positive cases, $50 \%$ (40/80) isolates were Dermatophytes, 36.25\% (29/80) were Nondermatophytic moulds and $13.75 \%$ (11/80) were Yeasts. Detailed distributions of the isolated fungus are presented in Table. IV. Most of the culture positive cases were found in DSO (73.5\%).

\begin{tabular}{|c|c|c|c|}
\hline \multicolumn{2}{|c|}{$\begin{array}{l}\text { Immunocompetent Group } \\
\mathrm{N}=205\end{array}$} & \multicolumn{2}{|c|}{$\begin{array}{c}\text { Immunocompromised } \\
\text { Group N=45 }\end{array}$} \\
\hline $\begin{array}{c}\text { Distribution of } \\
\text { patients }\end{array}$ & $\begin{array}{r}\text { Laboratory } \\
\text { confirmed }\end{array}$ & $\begin{array}{c}\text { Distribution } \\
\text { of patients }\end{array}$ & $\begin{array}{r}\text { Laboratory } \\
\text { confirmed }\end{array}$ \\
\hline \multirow{3}{*}{$\begin{array}{c}\text { Housewives, } \\
\text { Daily labours, } \\
\text { Farmers and } \\
\text { others } \\
(n=205)\end{array}$} & \multirow{3}{*}{$\begin{array}{c}30 \% \\
(61 / 205)\end{array}$} & $\begin{array}{l}\text { Diabetes } \\
\text { Mellitus } \\
(\mathrm{n}=25)\end{array}$ & $\begin{array}{c}52 \% \\
(13 / 25)\end{array}$ \\
\hline & & $\begin{array}{c}\text { Malignancy } \\
(\mathrm{n}=13)\end{array}$ & $\begin{array}{c}57 \% \\
(7 / 13)\end{array}$ \\
\hline & & $\begin{array}{c}\text { HIV } \\
\text { seropositive } \\
(n=7)\end{array}$ & $57 \%(4 / 7)$ \\
\hline $\begin{array}{r}\text { Table I: L } \\
\text { Diffe }\end{array}$ & 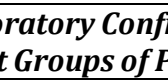 & med Onychon & $\begin{array}{l}\text { cosis in } \\
n t)\end{array}$ \\
\hline
\end{tabular}




\begin{tabular}{|c|c|c|}
\hline Clinical Types & $\begin{array}{c}\text { Suspected } \\
\text { Cases }\end{array}$ & $\begin{array}{c}\text { Confirmed } \\
\text { Cases }\end{array}$ \\
\hline $\begin{array}{c}\text { Distal Subungual } \\
\text { Onychomycosis (DSO) }\end{array}$ & 215 & 61 \\
\hline $\begin{array}{c}\text { Proximal Subungual } \\
\text { Onychomycosis (PSO) }\end{array}$ & 10 & 8 \\
\hline $\begin{array}{c}\text { White Superficial } \\
\text { Onychomycosis (WSO) }\end{array}$ & 8 & 5 \\
\hline $\begin{array}{c}\text { Candidial Onychomycosis } \\
\text { (CO) }\end{array}$ & 8 & 7 \\
\hline $\begin{array}{c}\text { Total Dystrophic } \\
\text { Onychomycosis (TDO) }\end{array}$ & 9 & $\mathbf{8 5}$ \\
\hline \multicolumn{2}{|c|}{ Total } \\
\hline Table II: Different Clinical Types of Diagnosed Cases of \\
Onychomycosis and their Distribution \\
\hline \multicolumn{2}{|c|}{} \\
\hline
\end{tabular}

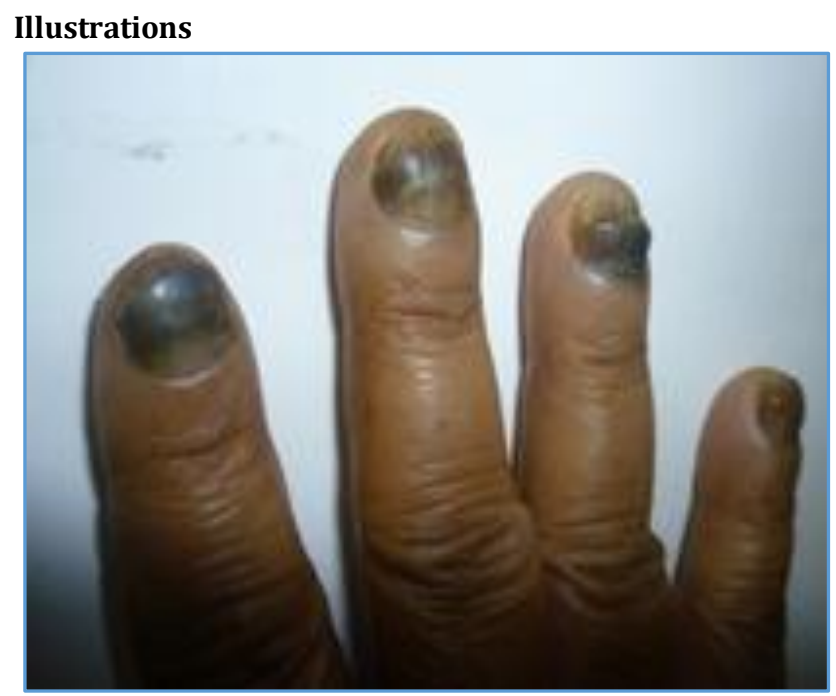

\begin{tabular}{|c|c|c|c|}
\hline Investigations & KOH (+) & KOH (-) & Total \\
\hline Culture (+) & 57 & 23 & 80 \\
\hline Culture (-) & 5 & 165 & 170 \\
\hline Total & $\mathbf{6 2}$ & $\mathbf{1 8 8}$ & $\mathbf{2 5 0}$ \\
\hline Table III: Correlation between KOH Finding and Culture \\
\hline
\end{tabular}

\begin{tabular}{|c|c|c|c|}
\hline \multicolumn{2}{|c|}{ Organisms } & Frequency & $\%$ \\
\hline \multirow{4}{*}{$\begin{array}{c}\text { Dermatophytes } \\
(50 \%)\end{array}$} & $\begin{array}{c}\text { Trichophyton } \\
\text { mentagrophytes } \\
\text { (TM) }\end{array}$ & 23 & 28.75 \\
\hline & $\begin{array}{l}\text { Trichophyton } \\
\text { rubrum(TR) }\end{array}$ & 12 & 15 \\
\hline & $\begin{array}{c}\text { Trichophyton } \\
\text { violaceum (TV) }\end{array}$ & 3 & 3.75 \\
\hline & $\begin{array}{l}\text { Epidermophyton } \\
\text { floccosum (EF) }\end{array}$ & 2 & 2.5 \\
\hline \multirow{3}{*}{$\begin{array}{l}\text { Candida } \\
(21.2 \%)\end{array}$} & $\begin{array}{c}\text { Candida } \\
\text { albicans }(\mathrm{CA})\end{array}$ & 4 & 5 \\
\hline & $\begin{array}{l}\text { Candida krusei } \\
\text { (CK) }\end{array}$ & 4 & 5 \\
\hline & $\begin{array}{c}\text { Candida } \\
\text { parapsilosis }(\mathrm{CP})\end{array}$ & 3 & 3.75 \\
\hline \multirow{9}{*}{$\begin{array}{l}\text { Nondermatophy } \\
\text { tic mould } \\
(36.8 \%)\end{array}$} & $\begin{array}{c}\text { Aspergillus } \\
\text { fumigatus }(\mathrm{AFu})\end{array}$ & 5 & 6.25 \\
\hline & $\begin{array}{l}\text { Aspergillus flavus } \\
\text { (AF) }\end{array}$ & 5 & 6.25 \\
\hline & $\begin{array}{l}\text { Aspergillus niger } \\
\text { (AN) }\end{array}$ & 4 & 5 \\
\hline & $\begin{array}{c}\text { Scopulariopsis } \\
\text { brevicaulis (SB) }\end{array}$ & 5 & 6.25 \\
\hline & $\begin{array}{c}\text { Scytalidium } \\
\text { hyalinum (SH) }\end{array}$ & 4 & 5 \\
\hline & $\begin{array}{c}\text { Rhizopus arrhizus } \\
\text { (RA) }\end{array}$ & 2 & 2.5 \\
\hline & Mucor spps. & 2 & 2.5 \\
\hline & $\begin{array}{l}\text { Acremonium } \\
\text { kiliense (AK) }\end{array}$ & 2 & 2.5 \\
\hline & Total & 80 & 100.0 \\
\hline
\end{tabular}

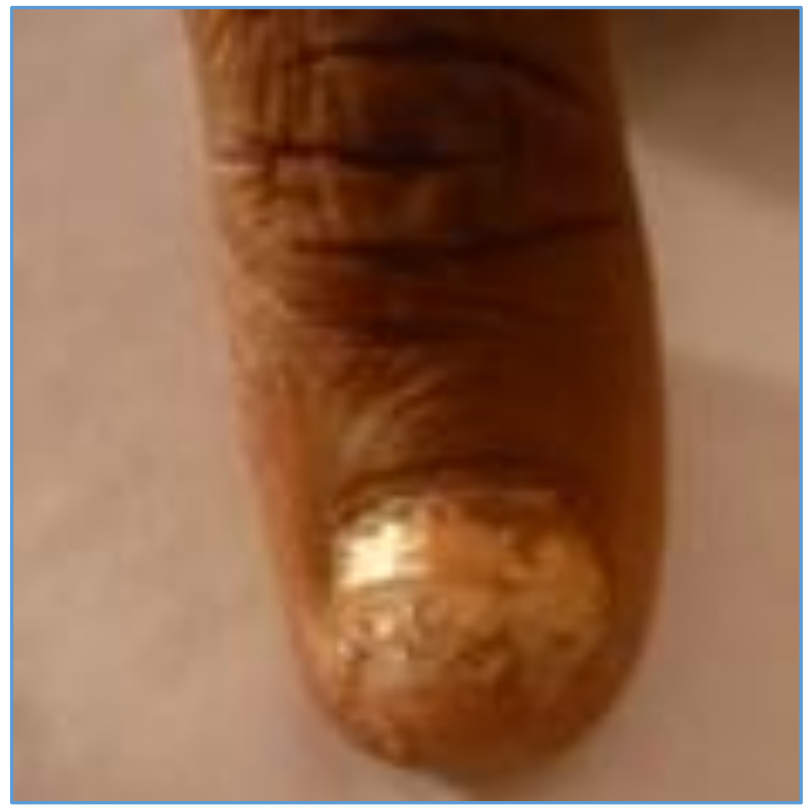

Image I: Distal Subungual Onychomycosis

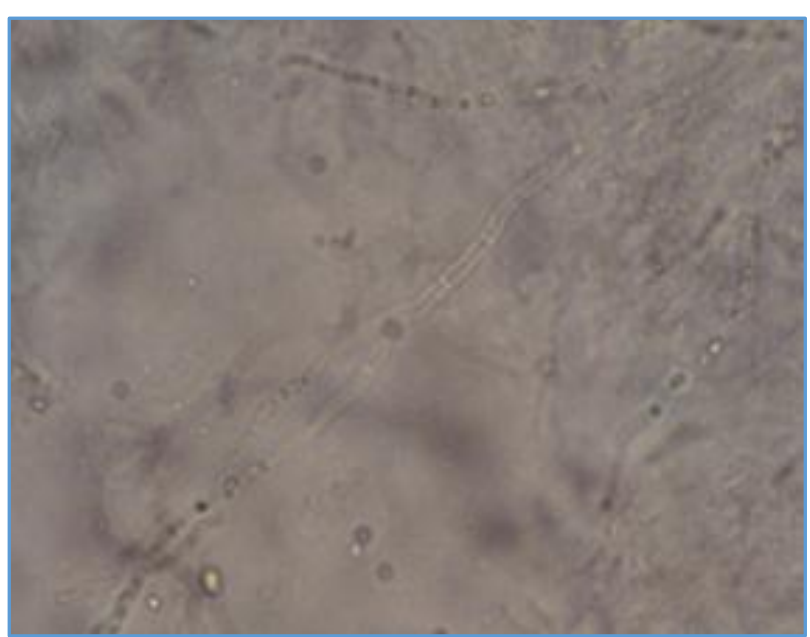

Image II: 20\% КОН Mount of the Nail Clipping showing Branched Septate Hyaline Hyphae 


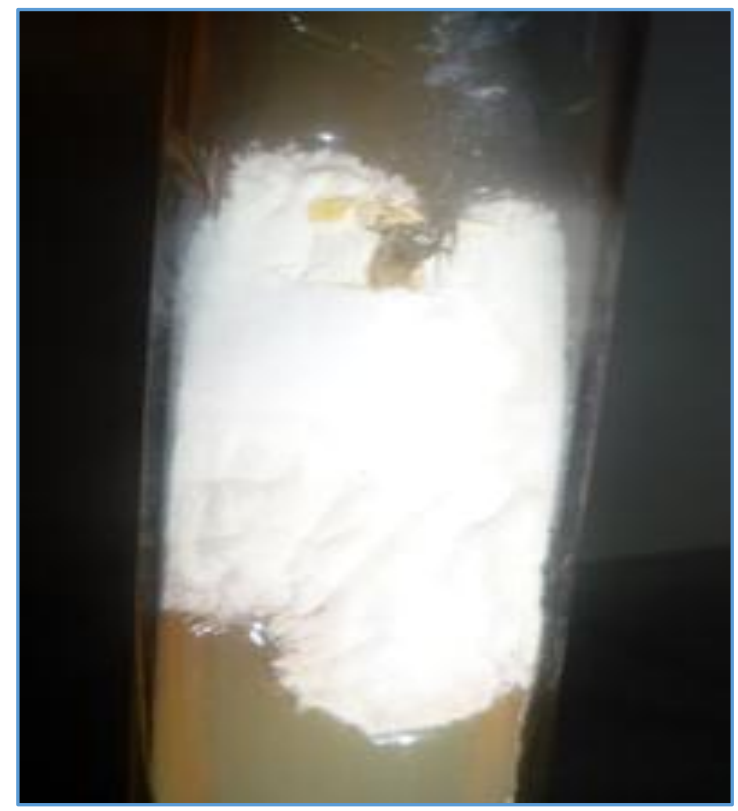

Image III: White Fluffy Colony in Culture of Trichophyton Mentagrophyte

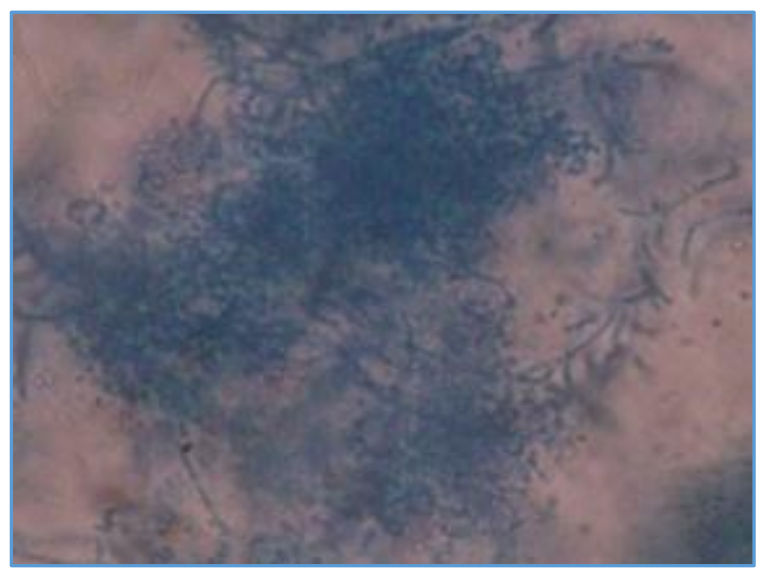

Image IV: LPCB Mount of T. Mentagrophyte

\section{DISCUSSION}

Onychomycosis being a chronic fungal infection of nail affects social, emotional and occupational functioning of the patient.[5] The present study highlights the prevalence of $\mathrm{OM}$ in Tripura where both nontribal and tribal populations live together in urban and rural set up. In general, hot and humid environment of the tropical and sub-tropical regions are best suited for the dermatophytic infections, which has been reported from different parts of India.[6,7] In the present study, the prevalence of OM has been estimated to be $34 \%$ among the patients attending the tertiary hospital. Prevalence rate varies from $3-26 \%$ in different regions of the world. ${ }^{[8,9]}$ Due to lack of general health awareness and favourable climatic conditions, the nail apparatus is susceptible to invasion by pathogenic fungus followed by their keratinolytic activity slowly progresses to disfigurement of finger/toenails leading to Onychomycosis.

The nail apparatus has certain immunological disadvantages like very low level of expression of Major Histocompatibility (MHC) class 1a antigen, local production of potent immunosuppressive agents, dysfunction of Antigen Presenting Cells (APC) and inhibition of Natural Killer (NK) cell activity, which lead to low cell mediated immune response following invasion of pathogens through the proximal nail fold and distal nail fold.[10] Structurally, the nail apparatus is well exposed to environment and prone to damage even following minor trauma. Out of 85 cases of $\mathrm{OM}$, male patients are found to be commonly affected than the females ( 62 vs. $23 ; 83 \%$ vs. $27 \%$ ), which may be due to their outdoor activity and physical labour thereby exposing themselves to repeated trauma of the nails, which predisposes to onychomycosis.[11,12] Considering the different age groups affected in our study, it is found that the commonest age group affected is between 46-55 years (31.7\%). This finding correlates well with other reports.[9] The lower prevalence in children below 15 years of age $(n=5)$ maybe due to less exposure to trauma and increased growth rate of the nails in children, which aborts the infection by the pathogenic fungi successfully.

Amongst the affected female populations, the high incidence of $\mathrm{OM}$ has been noticed in housewives could be due to frequent submerging of their hands in water.[12] In the present study, involvement of finger nails (64.7\%) are higher than the toe nails $(35.2 \%)$ whereas both the nails are affected in $5.2 \%$ of cases. Higher involvement of fingernails is reported by many other studies.[13,14] In the study, the occurrence of OM is $88 \%$ in DSO, which is the commonest clinical type.[15] Mild inflammation with focal parakeratosis, subungual hyperkeratosis and onycholysis, thickening or distortion of nail plate is seen in DSO (Image 1). The keratin of the hyponychium is infected first; gradually it progresses and involves nail bed and subsequently nail plate. The infection grows proximally whereas nail plate grows distally. [16] In the present study, culture confirmed onychomycosis are $34 \%$, which is in accordance with report from other study,[10] but the variations are much wider according to different studies.[15,16] Detection of fungal elements in direct microscopic examination is found to be less sensitive than the culture (Table III), which emphasises the importance of culture inoculation in all the suspected cases of OM.

Demonstration of fungal hyphae as well as isolation of pathogenic fungi from nail is difficult due to error in sampling technique. Conventionally, the material is obtained from the distal end of nail. But, the fact is that the pathogenesis advances proximally and although proximal sampling maybe uncomfortable for the patient, but it should be the norm as far as possible. For culture, the hyphae at the distal end are less likely to be viable and difficult to grow in culture. For this purpose, full thickness nail clip is to be obtained using nail clipper; subungual debris is helpful in cases of superficial white onychomycosis; culture sample obtained using dental drilling and curettage techniques are better techniques. It was suggested that a combination of curette and clipping would improve the yield.[17] Dermatophytes are the most commonly isolated pathogen (50\%) in the present study followed by nondermatophytic moulds $(36.25 \%)$ and yeasts like Candida species (13.75\%). Many other studies in different parts of India and abroad have reported dermatophytes as the commonest cause of Onychomycosis.[18,19,20,21] Onychomycosis caused by Trichophyton mentagrophyte $(28.75 \%)$ is the commonest followed by T. rubrum (15.0\%) (Table IV).

The finding is similar to a study done by Bhatia and Sharma. ${ }^{[22]}$ In several Indian studies, T. rubrum remain the commonest dermatophytes.[23] The predominant 
dermatophyte in a particular geographical area varies probably due to different geographical condition, environmental temperature, rainfall and humidity. T. rubrum is generally linked to chronic dermatophytosis.[23] The virulence factors like keratinolytic enzymes (e.g. hydrolase, keratinase and cysteine dioxygenase) has been reported.[24] The $\mathrm{T}$. mentagrophyte being more active destroyer than $\mathrm{T}$. rubrum.[21] Thus, the species identification is of importance to a clinician for the effective management and prognosis of the disease while treating Onychomycosis. In the present study, Candida albicans is isolated only in $5 \%$ cases like other countries. ${ }^{[24]}$ Yeasts generally invade damaged nails or nails in immunosuppressed conditions.[25] Nondermatophytic moulds (NDM) are isolated in $36.25 \%$ of the study subjects, which is slightly higher in some other studies.[10,24,25]

The accumulating evidences suggest that NDM is primary pathogen in OM lesion. ${ }^{[8]}$ The higher incidence maybe due to the climate in this area along with injury to the nails and thereby exposing it to the contaminant fungi.[6] In the study, $\mathrm{OM}$ among the HIV infected (or seropositive) individuals is $57 \%$, which is quite similar to the study done by Surjushe A, Kamath R.[24] In the present study, the $\mathrm{KOH}$ mount examination had missed 23 samples those have shown growth of fungus like yeasts and NDM in culture. Interestingly, in 5 (five) cases, fungal elements detection by $\mathrm{KOH}$ Mount was positive where Culture remained negative. It is probably due to presence of nonviable fungal elements in the specimen or error in media (i.e. faulty $\mathrm{pH}$, growth of contaminant). It has also been reported that $30-50 \%$ of microscopically identified onychomycosis cannot be cultivated and hence pathogen cannot be identified at the species level.[26]

\section{CONCLUSION}

Early diagnosis of onychomycosis is a challenge to the microbiologist. The sensitivity of microscopic detection technique using 20\% $\mathrm{KOH}$ mount varies from $48-80 \%$.[26] This leads to search of advanced techniques like various molecular diagnostic methods for rapid, stable and accurate alternative for identifying pathogenic fungi from the nail sample. Polymerase Chain Reaction (PCR) technique is presently undergoing evaluation and found that it can detect up to the species level within 48 hours.[27] In this regard, Matrix-Assisted LASER Desorption/Ionisation Time of Flight Mass Spectrometry (MALDI-TOF MS) is another promising technique. The sample preparation is simple and result is available within 24 hours.[10,28] Accumulated knowledge regarding pathogenesis of Onychomycosis emphasises the necessity of confirmation of diagnosis for effective treatment.

\section{REFERENCES}

1. John BE. Miscellaneous mycoses and algal infections. In: Kasper DL, Fauci AS, Longo DL, et al. eds. Harrison's principles of internal medicine. $16^{\text {th }}$ ed. New York: McGraw-Hill 2005:1191-92.

2. Westerberg DP, Voyack MJ. Onychomycosis: Current trends in diagnosis and treatment. Am Fam Physician. 2013;88(11):762-70.

3. Moore GS, Jaciow DM. Mycology for the clinical laboratory. Reston, Virginia: Reston Publishing Company Inc. 1979:120-3.
4. Chakrabarti A, Shivaprakash MR. Medical mycology laboratory procedures. Centre of Advanced Research in Medical Mycology (ICMR), Department of Microbiology, PGIMER, Chandigarh 2008:52-5.

5. Chan HH, Wong ET, Yeung CK. Psychosocial perception of adults with onychomycosis: a blinded, controlled comparison of 1,017 adult Hong Kong residents with or without onychomycosis. Biopsychosoc Med. 2014;8:15. doi:10.1186/1751-0759-8-15.

6. Raghavendra KR, Yadav D, Kumar A, et al. The nondermatophyte molds: Emerging as leading cause of onychomycosis in south-east Rajasthan. Indian Dermatol Online J. 2015;6(2):92-7.

7. Yadav P, Singal A, Pandhi D, et al. Clinico-mycological study of dermatophyte toenail onychomycosis in New Delhi, India. Indian J Dermatol. 2015;60(2):153-8.

8. Sobhanadri C, Rao DT, Babu KS. Clinical and mycological study of superficial fungal infections at Government General Hospital: Guntur and their response to treatment with Hamycin, Dermostatin and Dermamycin. Indian J Dermatol Venerol Leprol. 1970;36(6):209-14.

9. Karmakar S, Kalla G, Joshi KR, et al. Dermatophytoses in a desert district of Western Rajasthan. Indian J Dermatol Venereol Leprol. 1995;61(5):280-3.

10. Grover C, Khurana A. Onychomycosis: newer insights in pathogenesis and diagnosis. Indian J Dermatol Venereol Leprol. 2012;78(3):263-70.

11. Scher RK. Onychomycosis: a significant medical disorder. J Am Acad Dermatol. 1996;35(3 Pt 2):S2-5.

12. Murray SC, Dawber RP. Onychomycosis of toenails: orthopaedic and podiatric considerations. Australas J Dermatol. 2002;43(2):105-12.

13. Kaur R, Kashyap B, Bhalla P. Onychomycosis-epidemiology, diagnosis and management. Indian J Med Microbiol. 2008;26(2):108-16.

14. Veer P, Patwardhan NS, Damle AS. Study of onychomycosis: prevailing fungi and pattern of infection. Indian J Med Microbiol. 2007;25(1):53-6.

15. Rippon JW. Dermatophytosis and dermatomycoses. In: Rippon JW. ed. Medical mycology. $3^{\text {rd }}$ edn. Philadelphia: WB Saunders 1988:169-275.

16. Gupta M, Sharma NL, Kanga AK, et al. Onychomycosis: Clinico-mycologic study of 130 patients from Himachal Pradesh, India. Indian J Dermatol Venereol Leprol. 2007;73(6):389-92.

17. Neupane S, Pokhrel DB, Pokhrel BM. Onychomycosis: clinical pattern and prevailing fungi in Kathmandu. Nepal Med Coll J. 2011;13(3):193-6.

18. Malik NA, Raja N, Nasiruddin. Non-dermatophyte moulds and yeast as causative agents in onychomycosis. J Pak. Assoc Dermatol 2009;19:74-8.

19. Adhikari L, Das Gupta A, Pal R, et al. Clinico-etiologic correlates of onychomycosis in Sikkim. Indian J Pathol Microbiol. 2009;52(2):194-7.

20. Hull PR, Gupta AK, Summerbell RC. Onychomycosis: an evaluation of three sampling methods. J Am Acad Dermatol. 1998;39(6):1015-7.

21. Nenoff P, Kruger C, Ginter-Hanselmayer G, et al. Mycology - an update. Part 1: Dermatomycoses: causative agents, epidemiology and pathogenesis. J Dtsch Dermatol Ges. 2014;12(3):188-209. 
22. Bhatia VK, Sharma PC. Epidemiological studies on Dermatophytosis in human patients in Himachal Pradesh, India. Springerplus 2014;3:134.

23. Sadahiro A, Moraes JRF, Moraes MEH, et al. HLA in Brazilian Ashkenazic Jews with chronic dermatophytosis caused by Trichophyton rubrum. Braz J Microbiol 2004;35(1-2):69-73.

24. Surjushe A, Kamath R, Oberai C, et al. A clinical and mycological study of onychomycosis in HIV infection. Indian J Dermatol Venereol Leprol. 2007;73(6):397-401.

25. Musial CE, Cockerill FR, Roberts GD. Fungal infections of the immunocompromised host: clinical and laboratory aspects. Clin Microbiol Rev. 1988;1(4):349-364.
26. Graser Y, Czaika V, Ohst T. Diagnostic PCR of dermatophytes-an overview. J Dtsch Dermatol Ges. 2012;10(10):721-6.

27. Han HW, Hsu MM, Choi JS, et al. Rapid detection of dermatophytes and Candida albicans in onychomycosis specimens by an oligonucleotide array. BMC Infect Dis. 2014;14:581.

28. Erhard M, Hipler UC, Burmester A, et al. Identification of dermatophyte species causing onychomycosis and tinea pedis by MALDI-TOF mass spectrometry. Exp Dermatol. 2008;17(4):356-61. 